\title{
Genetic parameters for lactose percentage in the milk of Polish Holstein-Friesians
}

\author{
E. Ptak ${ }^{1,3}$, P. Brzozowski ${ }^{2}$ and J. Bieniek ${ }^{1}$ \\ ${ }^{1}$ Agricultural University of Krakow, Department of Genetics and Animal Breeding \\ Al. Mickiewicza 24/28, 30-059 Kraków, Poland \\ ${ }^{2}$ Warsaw Agricultural University, Department of Animal Breeding and Production, \\ Cattle Breeding Division \\ Nowoursynowska 166, 02-787 Warszawa, Poland
}

(Received 29 November 2011; revised version 27 March 2012; accepted 18 June 2012)

\begin{abstract}
Genetic parameters for lactose percentage in the milk of Polish Holstein-Friesian cows were estimated using 48,859 test day records from six lactations of 8,418 cows and the Gibbs sampling method. The multiple-trait random regression model was applied for data from the first and subsequent (up to the sixth) lactations treated as two traits.

Variance components and heritabilities changed in a similar way through the first and subsequent lactations, reaching the highest values at peripheries and relatively stable values in the middle of lactations. All estimates were smaller in the first than in the later parities. Heritabilities of daily lactose percentage ranged from 0.17 to 0.31 with a mean of 0.24 ( $\mathrm{SD}=0.034)$, and from 0.23 to 0.36 with a mean of $0.28(\mathrm{SD}=0.026)$ in first and subsequent lactations. Genetic correlations for lactose percentage between the same days of the first and subsequent parities were less than 0.30 , with the average equal to $0.26(\mathrm{SD}=0.047)$ and the minimum (less than 0.15$)$ occurring in the first days after calving.
\end{abstract}

KEY WORDS: lactose, heritability, random regression model, Legendre polynomials, Gibbs sampling, milk, dairy cows

\section{INTRODUCTION}

Lactose is a disaccharide found only in the milk of mammals. It comprises $4.8 \%$ to $5.2 \%$ of milk. Lactose plays a significant role as a special nutritive component and an important role in regulating the metabolism of young mammals.

\footnotetext{
$\overline{{ }^{3} \text { Corresponding author: e-mail: rzptak@cyf-kr.edu.pl }}$
} 
One of the main functions of lactose is its utilization as a fermentation substrate. In the dairy industry, lactose is needed to produce many fermented dairy products such as yoghurt, buttermilk, or cottage cheese. Lactose is also used in the food industry because of its particular physicochemical characteristics as compared with other sugars; for instance, it is able to carry flavours and colours, and it is not fermented by baker's or brewer's yeasts. The result is that lactose has been used in the production of sweetened condensed milk, sachet wafers, seasonings, and a range of baked and confectionery goods. A considerable amount of lactose is used as animal feed (in spray-dried whey). Lactose can be molded into tablets and pills, and the pharmaceutical industry takes advantage of this characteristic (Zadow, 1984).

Lactose production per cow increases with milk production. Synthesis of the $4.8 \%$ lactose in milk requires about the same feed energy as the $3.4 \%$ of protein and $4.1 \%$ of fat (Rensing et al., 2002; Strzetelski and Śliwiński, 2009). The rate of lactose synthesis largely determines the rate of water secretion into milk, because lactose is the major factor responsible for its osmolality. On the other hand, the fat and protein content in milk is determined by the level of water secretion and, therefore, indirectly by lactose synthesis (Miglior et al., 2006). Reist et al. (2002) showed that the ratio of fat to lactose was one of the most informative traits for precise estimation of energy status in large herds. In Canada, lactose has been used as a trait employed for calculating the energy value of milk in establishing the energy requirements for feeding recommendations (Miglior et al., 2007).

Several studies have examined the relationships between lactose contents and production and other economically important traits. In Canada, research on genetic relationships between lactose and milk production traits was done by Miglior et al. (2007). They concluded that the lactose percentage was not genetically correlated with milk yield (0.096) nor with the content of fat $(0.058)$ or protein $(0.017)$, but that it was negatively genetically correlated (-0.202) with somatic cell score (SCS). A moderate genetic correlation (-0.35) of lactose contents with SCS was presented by Gillon et al. (2010), who concluded that lactose percentage could be used jointly with SCS for genetic evaluation of udder health. Miglior et al. (2006) also performed an analysis of lactose to find its association with longevity, and found that cows with low lactose percentages were more likely to be culled than cows with a high lactose percentage. Buckley et al. (2003) observed that in the Irish dairy population, a higher lactose percentage was associated with increased pregnancy rate, so the level of lactose could be a useful tool for identifying cows at risk of poor reproduction. The relationships between the lactose content in milk and udder health or somatic cell count in milk have also been investigated (Brzozowski et al., 1999; Sloth et al., 2003; Wielgosz-Groth and Groth, 2003). Wielgosz-Groth and Groth (2003) noted that the lactose content was significantly lower in the milk of cows with clinical mastitis than in that of healthy cows.

Genetic parameters for lactose are rare (Welper and Freeman, 1992; Neja et al., 2006; Miglior et al., 2007; Samoré et al., 2007; Stoop et al., 2007; Loker 
et al., 2009). In the studies cited above, the heritability estimates for lactose percentage ranged from 0.17 to 0.63 and were similar to or slightly lower than the heritabilities for fat and protein percentages. Variation of lactose content is lower than the variation of fat and protein percentages, which means that the last two milk components are influenced much more by environmental factors such as feeding than the first. Based on this knowledge, the potential for genetic change in lactose percentage may also be less than for fat and protein percentages (Welper and Freeman, 1992).

In Poland the lactose content of cow milk has been recorded since 1998. The potential of lactose as an indirect indicator trait for female fertility and health is worth exploring, and the first step is to assess the genetic parameters for lactose. The objective of this study was to estimate the genetic parameters for lactose percentage in the first and subsequent (i.e. second to sixth) lactations of Polish Holstein-Friesians using Gibbs sampling and a random regression (RR) test day model with Legendre polynomials as covariates.

\section{MATERIAL AND METHODS}

\section{Material}

Data were obtained from the Central Laboratory of Milk Evaluation in Parzniew and the SYMLEK system and consisted of 48,859 test day records with lactose percentage (LAC\%) from the first six lactations of 8,418 Polish HolsteinFriesian (HF) cows. There were 6 test day records per cow on average. The cows were calved from 2002 to 2004 and were the daughters of 319 sires and 5,451 dams. There were 43 cows among dams that had their own records in the data file. The pedigree file contained 14,145 animals in total (cows and their parents). Only data from cows that calved for the first time between 18 and 48 months of age, test day yields recorded between 5 and 305 days in milk (DIM), and at least 4 test day records per herd-year-month of test (HYM) subclass were used. The data are described in Table 1, and average daily values of lactose percentage, in Figure 1.

Table 1. Description of the data used for analysis

\begin{tabular}{|c|c|c|c|}
\hline & \multicolumn{2}{|c|}{ Lactations } & \multirow{2}{*}{ Total } \\
\hline & first & later & \\
\hline No. of records & 15,039 & 33,820 & 48,859 \\
\hline No. of cows & 2,737 & 5,843 & 8,418 \\
\hline No. of records per cow & 5.5 & 5.8 & 5.8 \\
\hline No. of $\mathrm{HYM}^{1}$ & 2,022 & 4,788 & 6,810 \\
\hline No. of GGAS ${ }^{2}$ & 24 & 48 & 72 \\
\hline Mean of LAC $\%^{3}$ & $4.83_{\mathrm{sd}=023}$ & $4.70_{\mathrm{sd}=0.27}$ & $4.76_{\mathrm{sd}=0.27}$ \\
\hline Mean of milk yield, $\mathrm{kg}$ & $15.4_{\mathrm{sd}=5.06}^{\mathrm{sd}=0.23}$ & $17.5_{\mathrm{sd}=6.51}^{\mathrm{sd}=0.27}$ & $16.8_{\mathrm{sd}=6.18}^{\mathrm{sd}=0.27}$ \\
\hline
\end{tabular}




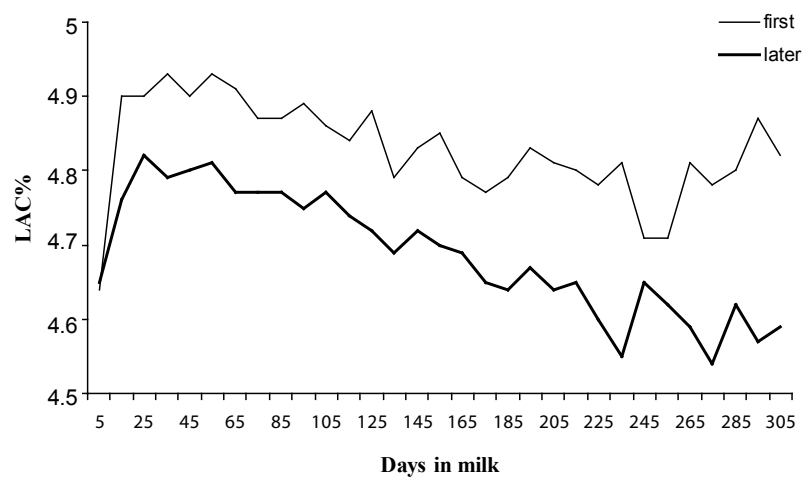

Figure 1. Average lactose percentage (LAC\%) in first and later lactations of cows

\section{Model}

The two-trait RR model was used for estimation of genetic parameters for daily lactose percentage in milk of first and subsequent lactations. In matrix notation, the model can be written as:

$$
\mathrm{y}=\mathrm{Hh}+\mathrm{Xb}+\mathrm{Za}+\mathrm{Wp}+\mathrm{e}
$$

where: $\mathrm{y}_{1}=\left[\mathrm{y}_{1}^{\prime} \mathrm{y}_{2}^{\prime}\right]^{\prime}, \mathrm{h}=\left[\mathrm{h}_{1}^{\prime} \mathrm{h}_{2}^{\prime}\right]^{\prime}, \mathrm{b}=\left[\mathrm{b}_{1}^{\prime} \mathrm{b}_{2}^{\prime}\right]^{\prime}, \mathrm{a}=\left[\begin{array}{ll}\mathrm{a}_{1}^{\prime} & \mathrm{a}_{2}^{\prime}\end{array}\right]^{\prime}, \mathrm{p}=\left[\mathrm{p}_{1}^{\prime} \mathrm{p}_{2}^{\prime}\right]^{\prime}$, $\mathrm{e}=\left[\mathrm{e}_{1} \mathrm{e}_{2}\right]^{\prime}$ and $\mathrm{H}, \mathrm{X}, \mathrm{Z}$ and $\mathrm{W}$ are direct sums of matrices, that is, $\mathrm{H}=\mathrm{H}_{1} \oplus \mathrm{H}_{2}, \mathrm{X}$ $=\mathrm{X}_{1} \oplus \mathrm{X}_{2}, \mathrm{Z}=\mathrm{Z}_{1} \oplus \mathrm{Z}_{2}, \mathrm{~W}=\mathrm{W}_{1} \oplus \mathrm{W}_{2}$.

The vector $\mathrm{y}_{t}$ contains test day percentages of lactose in first $(\mathrm{t}=1)$ or subsequent $(t=2)$ lactations. Similarly, $h_{t}$ - the vector of fixed herd-year-month of test (HYM) effects in lactation $t, b_{t}$ - the vector of fixed regression coefficients within the genetic group by age at calving by season of calving (GGAS) subclasses, $a_{t}$ - the vector of random regression coefficients for animal genetic effects, $p_{t}$ - the vector of random regression coefficients for permanent environmental effects, and $e_{t}$ - the vector of random residual effects, where $t=1,2$. The matrices $H_{t}, X_{t}, Z_{t}$ and $\mathrm{W}_{\mathrm{t}}$ (for $\left.\mathrm{t}=1,2\right)$ are incidence matrices which assign observations from the first $(\mathrm{t}=1)$ or subsequent $(\mathrm{t}=2)$ lactations to effects in the model.

The effect of HYM was included in the model instead of the effect of herd-test day (HTD) because there were too many very small classes for the latter effect. Two seasons of calving (April-September, October-March) and three genetic groups (up to $25 \%$ of HF genes, between $25 \%$ and $75 \%$ of HF genes, more than $75 \%$ of HF genes) were assumed. There were four age classes created in first lactations $(t=1)$ and 8 age classes in subsequent lactations $(\mathrm{t}=2)$. Fixed and random regressions were modeled by $4^{\text {th }}$-order Legendre polynomials (Kirkpatrick et al., 1994).

The (co)variances for random effects in the model were assumed as $V(a)=A \otimes G$, $\mathrm{V}(\mathrm{p})=\mathrm{I} \otimes \mathrm{P}$ and $\mathrm{V}(\mathrm{e})=\sum^{+} \mathrm{R}^{\mathrm{ts}, \mathrm{s}}$, where $\mathrm{G}$ and $\mathrm{P}$ denote (co)variance matrices of the RR 
coefficients for animal genetic and permanent environmental effects, respectively, $\mathrm{A}$ is the additive genetic relationship matrix among the animals, and I is the identity matrix. Matrix $\mathrm{R}^{\mathrm{t}, \mathrm{s}}$ is a diagonal residual matrix with elements on the diagonal equal to residual variances that depend on the time period $(s=1,4)$ within each parity $(t=1,2)$. The same time periods were defined within first and subsequent parities (5 to 45 DIM, 46 to 105 DIM, 106 to 205 DIM and 206 to 305 DIM). It was also assumed that residual effects on different DIM were uncorrelated within and between cows. The symbol $\otimes$ denotes the Kronecker product and the symbols $\oplus$ or $\sum^{+}$are the direct sum of matrices.

\section{Estimation of genetic parameters}

The Gibbs sampling algorithm was used to generate 200,000 samples from marginal posterior distributions (Jamrozik and Schaeffer, 1997). There were 118 (co)variance components generated in each run of iteration (55 for $\mathrm{G}, 55$ for $\mathrm{P}$ and 8 for R). The first 20,000 samples were discarded as the burn-in period and the remaining 180,000 samples were used for calculations. Means of (co)variance matrices were used for estimation of both genetic and permanent environmental variances of LAC $\%$ on every DIM, and covariances between LAC $\%$ on two days in one lactation, as well as between LAC\% on the same day in different lactations. Genetic and permanent environmental variances for 305-d lactation yield and covariance between lactations were also calculated using the formula given by Jamrozik and Schaeffer (1997).

\section{RESULTS AND DISCUSSION}

In this study the lactation curves for average test day lactose percentage within parities resembled the shape of the lactation curve for milk yield, with the maximum value before 60 days in milk and a gradual decrease over the rest of lactation (Figure 1). Interestingly, the average lactation curves of lactose percentage differed in shape from the curves for other milk components, i.e. fat or protein, expressed as percentages.

The average content of lactose across parities was 4.76, with higher and less variable values in the first than in subsequent lactations (Table 1). A similar decreasing trend for lactose percentage in subsequent lactations was observed by Miglior et al. (2006). Lactose percentages reported by Sloth et al. (2003) for Danish Holsteins and by Park et al. (2007) for Korean Holsteins were on a level similar to that of Polish Holstein-Frisians. Lower lactose percentages were reported by Miglior et al. (2006) and Loker et al. (2009) in Canadian Holsteins and by Stoop et al. (2007) in Dutch Holsteins. Welper and Freeman (1992) observed higher lactose contents in US Holsteins, and they noted that this milk component 
gradually declined as age at calving increased.

Estimates of genetic parameters for lactose percentage in milk and its relationship with production traits in dairy cattle are scant in the literature (Welper and Freeman, 1992; Neja et al., 2006; Miglior et al., 2007; Samoré et al., 2007; Stoop et al., 2007). The genetic and permanent environmental variances for lactose percentage in each DIM of first and subsequent lactations are shown in Figure 2. Genetic variance was higher in the first lactation than in subsequent ones, except for the last month of parity (270-305 days), and changed in a similar way in both groups of lactations. The values of genetic variance were highest at the beginning of lactations, almost stable between 45 and 270 DIM, with a slowly increasing trend thereafter. These variances ranged from 0.035 to 0.095 in first, and from 0.028 to 0.062 in subsequent lactations, with averages of 0.039 and $0.034(\mathrm{SD}<0.01)$, respectively (Figure 2$)$.

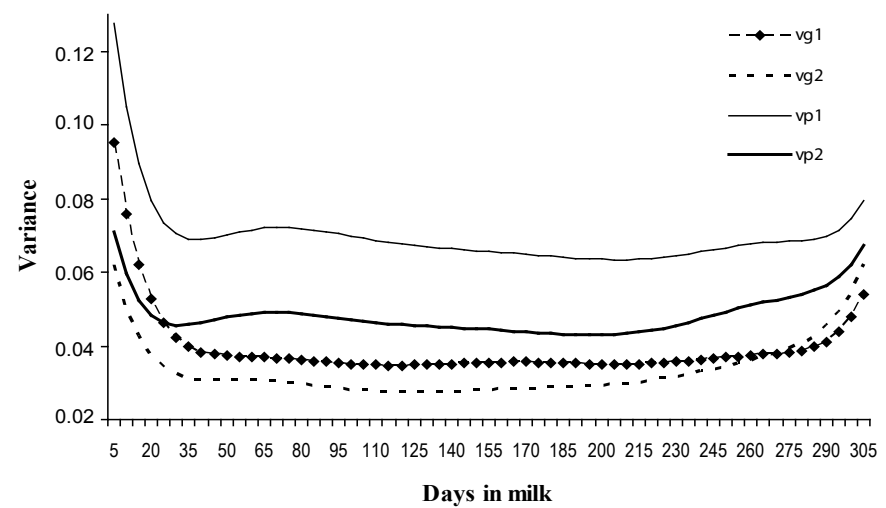

Figure 2. Genetic (vg) and permanent environmental (vp) variance for lactose percentage in 5-305 days in milk by parity (1-first, 2-later)

Permanent environmental variance for $\mathrm{LAC} \%$ was higher than genetic variance (by about 0.023 on average) but less variable during lactation (Figure 2 ). The values of permanent environmental variance were much lower in later lactations than in first parities. In both groups of lactations, variation was highest during the first 20 DIM. At the end of the 305d lactation, these variances represented about $60 \%$ of the values from the very beginning in the case of first lactations, and reached values similar to those observed at the very beginning in the case of subsequent lactations. The averages for permanent environmental variances were equal to 0.070 and $0.048(\mathrm{SD}<0.009)$ in first and subsequent lactations, respectively.

Figure 3 shows how residual variance changed in 4 assumed intervals during 305 days of both groups of lactations. These variances ranged from 0.033 to 0.109 in first and from 0.027 to 0.054 in later lactations. They reached the highest values in the first interval (5-45 DIM); in the second interval (46-105 DIM) they decreased by about half, and were lowest in the third interval (106-205 DIM). 
As in case of genetic and permanent environmental variances, residual variance in first lactations was higher than in later parities.

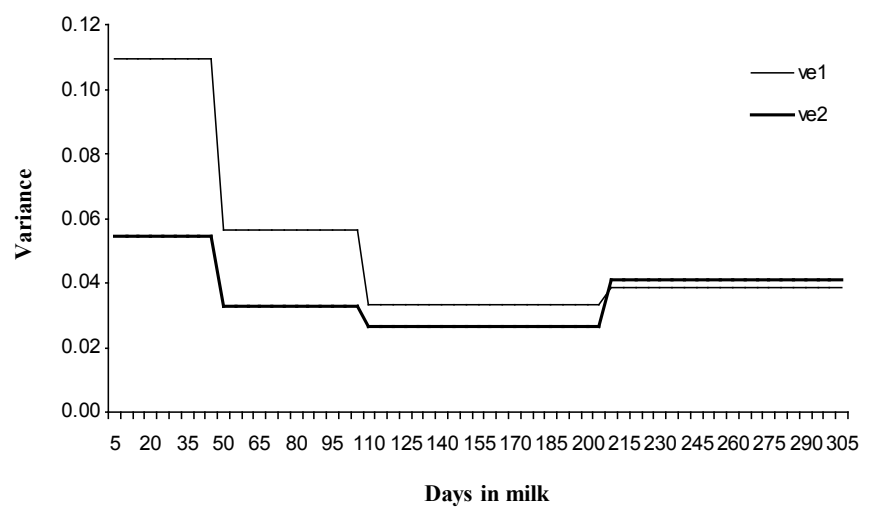

Figure 3. Residual variance (ve) for lactose percentage in 5-305 days in milk by parity (1 first, 2-later)

All variances (genetic, permanent environmental, and residual) showed higher values at peripheries of lactation than in its middle. According to Misztal et al. (2000) it is possible that fewer data points at the beginning and at the end of lactation together with insufficient flexibility of $4^{\text {th }}$ order polynomials used as random regressions result in a poorer fit in the extremes of DIM and better fit in the middle part of lactation. The only study found in the literature that presents daily genetic and permanent environmental variances for lactose percentage in the first three lactations is a study by Miglior et al. (2007). These authors obtained variances that changed in a way similar to the variances in Figure 2: higher at peripheries and quite constant over the remaining period of lactation. Genetic variance estimated by Miglior et al. (2007) was within the range or slightly lower than that in this paper. Permanent environmental variance was lower than genetic variance in their study, in contrast to the results in our study. Miglior et al. (2007) assumed residual variance to be constant within 4 stages of lactation defined similarly as in our work, and they obtained much smaller variance for residuals in the first three lactations, with the lowest values in the middle period of lactation, which is in agreement with our results.

Heritabilities of lactose percentage in successive DIM of the first and subsequent lactations are presented in Figure 4 . The estimated $\mathrm{h}^{2}$ values were from 0.17 to 0.31 with a mean of $0.24(\mathrm{SD}=0.034)$ in first lactations and from 0.23 to 0.36 with a mean of $0.28(\mathrm{SD}=0.026)$ in later lactations. They were in the range of heritabilities reported in the literature (Welper and Freeman, 1992; Neja et al., 2006; Miglior et al., 2007, Samoré et al., 2007; Stoop et al., 2007). Lactose percentage in milk was more heritable when cows calved for the second or next time than for primiparous cows. The average difference between daily $\mathrm{h}^{2}$ 


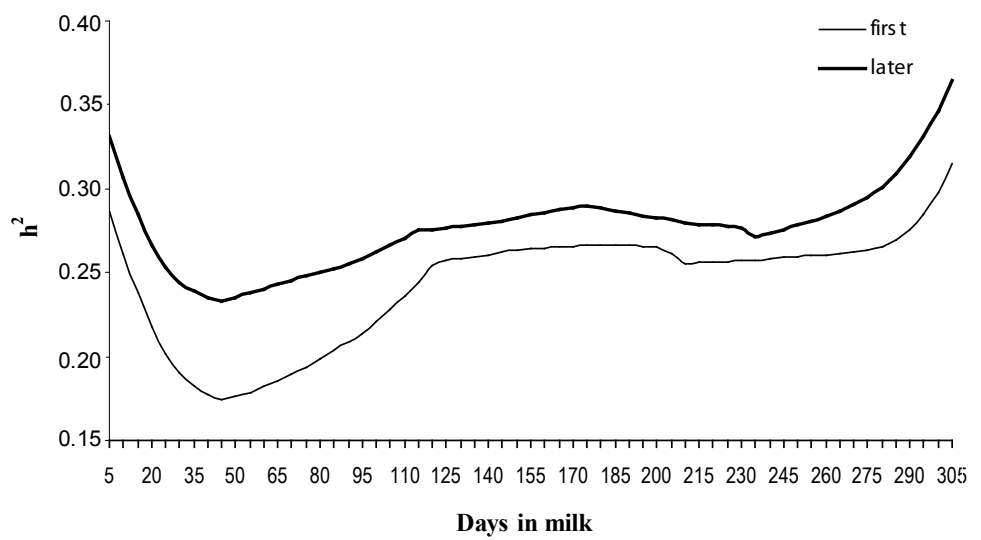

Figure 4. Heritability $\left(\mathrm{h}^{2}\right)$ of lactose percentage during first and later lactations

in the two groups of lactations was 0.03 , with the smallest difference in the middle part of lactation and the largest during the second and third month after calving. Generally, heritabilities changed in a similar way in subsequent DIM for both groups of lactations. During the first post-partum month, heritability decreased greatly, reaching the lowest value in the middle of the second month after calving. Heritability values were relatively stable from month 5 through month 9 of both first and subsequent lactations. The high heritability values at the peripheries can be explained partly by the occurrence of the highest genetic variation during these parts of the lactations.

The range of estimates of the heritability of daily lactose percentage reported in the literature is broad and depends on the population considered, number of animals, parity number, type of model, and method used for variance component estimation (Welper and Freeman, 1992; Neja et al., 2006; Miglior et al., 2007; Samoré et al., 2007; Stoop et al., 2007). The highest heritability (0.63) was obtained by Stoop et al. (2007) in the Dutch population. Average daily heritabilities for lactose percentage in the first three lactations estimated by Miglior et al. (2007) were moderately high (0.48-0.51) but still much higher than in this study. Gillon et al. (2010) obtained a mean heritability of 0.42 for daily lactose content in the population of dairy cows in Belgium, whereas Samoré et al. (2007) found much lower heritability $(0.17)$ for that trait in Italian Brown Swiss. The first-parity heritability for lactose percentage estimated by Neja et al. (2006) for Polish Holstein-Friesians is in accordance with the estimate in this study, but the opposite tendency was observed for values of $\mathrm{h}^{2}$ in later lactations; Neja et al. (2006) obtained lower heritability in the second and third lactations than in the first parity. They analysed test day data applying a similar linear model but a different method, i.e. REML. Welper and Freeman (1992) obtained a heritability of 0.43-0.53 for lactose percentage, depending on the model used in the analysis of lactational traits. 
They observed that estimates of $\mathrm{h}^{2}$ for LAC $\%$ increased when SCS was included in the linear model as a covariate, and they inferred that this probably was due to a relationship between mastitis and lactose percentage. Similar conclusions that the lactose content in milk decreased with increasing severity of udder infection were drawn by Berning and Shook (1992), Harmon (1994), Miglior et al. (2007), and Gillon et al. (2010).

The heritabilities of lactation LAC\% based on test day data were also calculated: 0.35 and 0.39 for first and subsequent parities, respectively. They were slightly higher than the maximum estimates of daily heritability for lactose percentage. The increased heritability of $305-\mathrm{d}$ production or content might be explained by the possibility that residual variance for the entire lactation might be underestimated when taking an overall value of all DIM. Higher lactational heritabilities of traits as compared with daily heritabilities have been observed by other authors (Stoop et al., 2007).

Genetic correlations for daily lactose percentage between the same DIM of first and later parities are shown in Figure 5. They were relatively low (less than 0.30 ), especially when compared with genetic correlations for milk yield. The average value of genetic correlation was $0.26(\mathrm{SD}=0.047)$, with the minimum during the first days after calving. During the first two months they rose rapidly and during the rest of the 305-day lactation they were more stable. The genetic correlation for lactational LAC\% between first and subsequent parities calculated during the first days after calving. During the first two months they rose rapidly and during the rest of the 305-day lactation they were more stable. The genetic correlation for lactational LAC $\%$ between first and subsequent parities calculated with the use of daily variance components was higher than the correlations in particular DIM and equaled 0.33 .

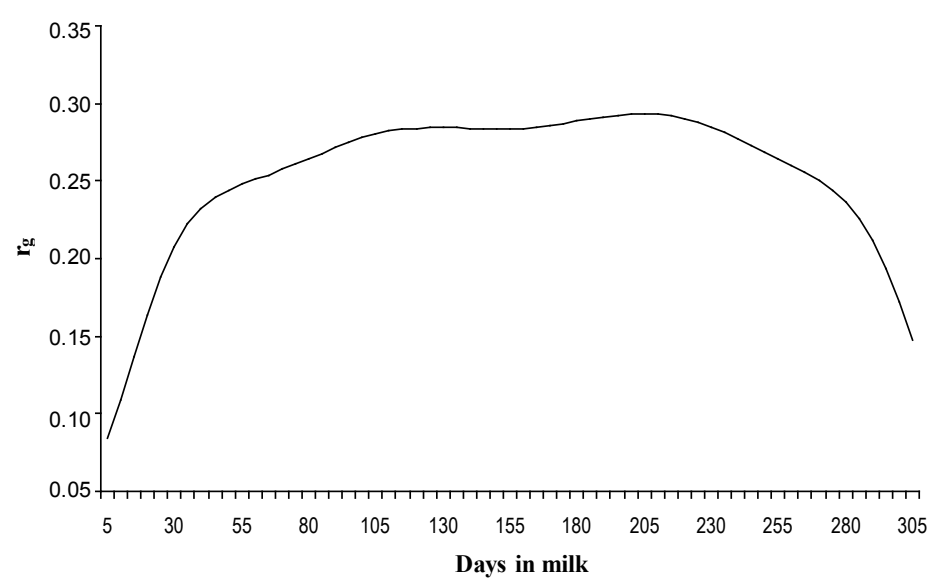

Figure 5. Genetic correlations $\left(\mathrm{r}_{\mathrm{g}}\right)$ for lactose percentage between first and later parities 
Genetic correlations among the first three parities for lactose percentage were also presented in the paper by Miglior et al. (2007). These correlations were much higher than the results in our study. In their work, correlations were equal to $0.76-0.85$ on average and were similar to corresponding values for milk yield in Canadian Holsteins. The much lower genetic correlations for Polish HolsteinFriesians could be due in part to methodological differences: they were calculated not between adjacent parities but between first and subsequent ones, that is, second to sixth lactations; the relationship between first and second parities was much stronger than between first and later lactations such as the fifth or sixth ones. Small correlations between the same days in different lactations as well as between lactations indicated a rather weak genetic relationship among lactose percentages in first and subsequent parities.

\section{CONCLUSIONS}

The heritability of lactose percentage in the milk of Polish Holstein-Friesians was moderate with slightly higher values in subsequent, that is, second to sixth lactations than in the first lactation. The changes of heritabilities for lactose percentage through both groups of lactations resembled the shape of changes for milk trait heritabilities: higher values at the peripheries and lower values in the middle part of lactations. Genetic correlations between lactose percentage in the same days in milk of first and subsequent lactations were low $(<0.30)$.

The results suggest that in genetic evaluation of Holstein-Frisians for lactose content in milk, records from at least the first two parities should be analysed rather than from first parities only. Considering the estimated values of genetic parameters, little genetic gain might be expected for lactose percentage.

\section{ACKNOWLEDGMENTS}

The authors thank Dr. Janusz Jamrozik for providing the FORTRAN programmes for variance component estimation.

\section{REFERENCES}

Berning L.M., Shook G.E., 1992. Prediction of mastitis using milk somatic cell count, N-Acetyl- $\beta$ D-glucosaminidase, and lactose. J. Dairy Sci. 75, 1840-1848

Brzozowski P., Ludwiczuk K., Zdziarski K., 1999. Somatic cell count in milk of cows covered with milk recording system in central region of Poland (in Polish). Prz. Hod. 44, 83-90 
Buckley F., O’Sullivan K., Mee J. F., Evans R. D., Dillon P., 2003. Relationships among milk yield, body condition, cow weight and reproduction in spring-calved Holstein-Friesians. J. Dairy Sci. $86,2308-2319$

Gillon A., Bastin C., Soyeurt H., Gengler N., 2010. Genetic parameters of mastitis-correlated milk components in first parity dairy cows. In: Proceedings of the $9^{\text {th }}$ World Congress on Genetics Applied to Livestock Production on http://www.kongressband.de/wcgalp2010/

Harmon R.J., 1994. Physiology of mastitis and factors affecting somatic cell counts. J. Dairy Sci. $77,2103-2112$

Jamrozik J., Schaeffer L.R., 1997. Estimates of genetic parameters for a test day model with random regressions for yield traits of first lactation Holsteins. J. Dairy Sci. 80, 762-770

Kirkpatrick M., Hill W.G., Thompson R., 1994. Estimating the covariance structure of traits during growth and ageing, illustrated with lactation in dairy cattle. Genet. Res. (Camb.) 64, 57-69

Loker S.F., Bastin C., Miglior F., Sewalem A., Fatehi J., Schaeffer L.R., Jamrozik J., 2009. Genetic parameters of body condition score and milk production traits in Canadian Holsteins. In: Dairy Cattle Breeding and Genetics Committee Meeting, Centre for Genetic Improvement of Livestock, University of Guelph (Canada), pp. 11

Miglior F., Sewalem A., Jamrozik J., Bohmanova J., Lefebvre D.M., Moore R.K., 2007. Genetic analysis of milk urea nitrogen and lactose and their relationships with other production traits in Canadian Holstein cattle. J. Dairy Sci. 90, 2468-2479

Miglior F., Sewalem A., Jamrozik J., Kistemaker G., Lefebvre D.M., Moore R.K., 2006. Genetic analysis of MUN and lactose and their relationships with economically important traits in Canadian Holstein cattle. Interbull Bull. 35, 58-63

Misztal I., Strabel T., Jamrozik J., Mäntysaari E. A., Meuwissen T.H.E., 2000. Strategies for estimating the parameters needed for different test-day models. J. Dairy Sci. 83, 1125-1134

Neja W., Sawa A., Piwczyński D., 2006. Heritability, genetic and phenotypic correlations and repeatability coefficients for daily yield, composition and cytologic quality of cow milk in the first three lactations of Friesian cows from Pomorze and Kujawy regions (in Polish). Pr. Mat. Zoot. 63, 59-68

Park Y.K., Koo H.C., Kim S.H., Hwang S.Y., Jung W.K., Kim J.M., Shin S., 2007. The analysis of milk components and pathogenic bacteria isolated from bovine raw milk in Korea. J. Dairy Sci. 90, 5405-5414

Reist M., Erdin D., von Euw D. et al., 2002. Estimation of energy balance at the individual and herd level using blood and milk traits in high-yielding dairy cows. J. Dairy Sci. 85, 3314-3327

Rensing S., Pasman E., Reinhardt F., Feddersen F., 2002. New total merit index RZG for Holsteins in Germany with more emphasis on herd life. Interbull Bull. 29, 147-149

Samoré A.B., Romani C., Rossoni A., Frigo E., Pedron O., Bagnato A., 2007. Genetic parameters for casein and urea content in the Italian Brown Swiss dairy cattle. Ital. J. Anim. Sci. 6, Suppl. $1,201-203$

Sloth K.H.M.N., Friggens N.C., Løvendahl P., Andersen P.H., Jensen J., Ingvartsen K.L., 2003. Potential for improving description of bovine udder health status by combined analysis of milk parameters. J. Dairy Sci. 86, 1221-1232

Stoop W.M., Bovenhuis H., van Arendonk J.A.M., 2007. Genetic parameters for milk urea nitrogen in relation to milk production traits. J. Dairy Sci. 90, 1981-1986

Strzetelski J., Śliwiński B., 2009. The Nutrient Requirements for Cattle. In: Nutrient Requirements for Ruminants (in Polish). National Research Institute of Animal Production. Kraków, pp. $21-25$

Welper R.D., Freeman A.E., 1992. Genetic parameters for yield traits of Holsteins, including lactose and somatic cell score. J. Dairy Sci. 75, 1342-1348 
Wielgosz-Groth Z., Groth I., 2003. Effect of the udder health on the composition and quality of quarter milk from Black-and-White cows. EJPAU 6 (2) http://www.ejpau.media.pl/volume6/ issue 2/animal/abs-01.html

Zadow J.G., 1984. Lactose: properties and uses. J. Dairy Sci. 67, 2654-2679 